\title{
Pengaruh Budaya Kerja terhadap Komitmen Karyawan PT Indofood CBP Sukses Makmur Tbk Cabang Bandung Divisi Noodle
}

\author{
Anne Hermayanti \\ Departemen Manajemen Fakultas Ekonomi dan Manajemen \\ Institut Pertanian Bogor \\ Kampus Darmaga Bogor 16680 \\ Siti Rahmawati \\ Departemen Manajemen Fakultas Ekonomi dan Manajemen \\ Institut Pertanian Bogor \\ Kampus Darmaga Bogor16680 \\ e-mail: sitirahmawatiipb@gmail.com
}

\begin{abstract}
PT Indofood CBP Sukses Makmur Branch Bandung Noodle Division is a company that realizes the importance of work culture and commitment. It is proven by the work culture that the company have implemented in order to guarantee better quality work result, and increase the satisfaction of employees' work. The objectives of this study are 1) identifying the work culture at PT. Indofood CBP Sukses Makmur Branch Bandung Noodle Division; 2) identifying work commitments on PT. Indofood CBP Sukses Makmur Branch Bandung Noodle Division; and 3) analyzing the influence of work culture with respect to the commitment of employees in PT Indofood CBP Sukses Makmur Branch Bandung Noodle Division. This research shows that Noodle Divsion of the company in Bandung applies excellent work culture and the employees commit. The work culture that is based on excellent, discipline, integrity, innovative, and respect gives positive and significant impacts on employees' commitment, while unity doesn't give significant impact on employees' commitment.

Keyword: work culture, employee commitment, PT Indofood CBP Prosperous Successes Tbk Bandung branch division of the noodle
\end{abstract}

\begin{abstract}
ABSTRAK
PT Indofood CBP Sukses Makmur Tbk Cabang Bandung Divisi Noodle, merupakan perusahaan yang menyadari pentingnya budaya kerja dan komitmen, terbukti dengan adanya budaya kerja yang dibuat di perusahan tersebut agar menjamin hasil kerja dengan kualitas yang lebih baik, meningkatkan kepuasan kerja karyawan. Tujuan penelitian ini adalah 1) mengidentifikasi budaya kerja pada PT Indofood CBP Sukses Makmur Tbk Cabang Bandung Divisi Noodle; 2) mengidentifikasi komitmen kerja pada PT Indofood CBP Sukses Makmur Tbk Cabang Bandung Divisi Noodle; dan 3) menganalisis pengaruh budaya kerja terhadap komitmen karyawan di PT Indofood CBP Sukses Makmur Tbk Cabang Bandung Divisi Noodle. Hasil penelitian menunjukan bahwa Divisi Noodle perusahaan tersebut menerapkan budaya kerja excellent dan karyawan melakukan secara komitmen. Budaya kerja excellent, discipline, integrity, innovative, respect berpengaruh positif dan signifikan terhadap komitmen karyawan, sedangkan unity tidak signifikan terhadap komitmen karyawan.

Kata kunci: budaya kerja, komitmen karyawan, PT Indofood CBP Sukses Makmur Tbk Cabang Bandung Divisi Noodle
\end{abstract}




\section{Pendahuluan}

Perusahaan dalam menjalankan usahanya selalu berdampingan dengan masyarakat karena perusahaan memiliki peran ganda yaitu sebagai produsen yang memerlukan masyarakat dan sebagai konsumen pendukung kelancaran usahanya. Oleh karena itu, terjadi hubungan timbal balik dan saling mempengaruhi antara perusahaan, masyarakat dan pemerintah. Begitu juga perusahaan dan karyawan merupakan dua hal yang tidak bisa dipisahkan, masing-masing mempunyai tujuan. Perusahaan dalam menjalankan bisnisnya, mengusahakan integrasi antar tujuan perusahaan dan karyawan dengan kebutuhan masing-masing pihak. Salah satu faktor yang menentukan berhasil tidaknya bisnis perusahaan adalah sumber daya manusianya. Keberhasilan perusahaan diukur oleh kemampuan perusahaan mencapai sasaran yang diharapkan baik dalam hal pertumbuhan, keuntungan atau kebertahanan (survival) untuk jangka pendek maupun jangka panjang (Mustika 2012).

Budaya kerja memiliki peranan penting di dalam organisasi. Budaya ini merupakan salah satu faktor yang mempengaruhi kinerja karyawan dalam suatu perusahaan.Faktor ini sangat erat kaitannya dalam meningkatkan kinerja karyawan. Dengan terciptanya budaya kerja yang baik dan ditunjang oleh kerja sama diantara karyawan, maka akan tercapai hasil yang dapat meningkatkan kinerja karyawan (Gibson 1996). Budaya adalah cara manusia memberikan respon terhadap lingkungannya.Budaya merupakan pola asumsi yang diciptakan, ditemukan, atau dikembangkan agar orang dapat menyesuaikan diri dengan kehidupan organisasi (Ivancevich et al. 2005). Budaya menyangkut moral, sosial, norma-norma perilaku yang mendasarkan pada kepercayaan, kemampuan dan prioritas anggota organisasi (Moeljono 2005). Budaya yang melekat pada masing-masing individu pada saat melaksanakan pekerjaannya,akan menjadi budaya yang diyakini oleh kelompok jika budaya tersebut diterapkan secara berkesinambungan saat melakukan pekerjaan dan sering disebut budaya kerja (Kurniawan et al. 2012).

PT Indofood CBP Sukses Makmur Tbk adalah perusahaan yang bergerak dibidang pengolahan makanan dan minuman yang didirikan pada tahun 1971. PT Indofood CBP Sukses Makmur Tbk mulai bergerak di pasar Internasional dengan mengekspor mi instan ke beberapa negara ASEAN, Timur Tengah, Hongkong, Taiwan, China, Belanda, Inggris, Jerman, Australia, dan beberapa negara di Afrika. Selain itu sampai saat ini terdapat 16 pabrik yang tersebar di kota-kota besar di Indonesia salah satunya yaitu PT Indofood CBP Sukses Makmur Tbk Cabang Bandung Divisi Noodle di kota Bandung, beralamat di Jl Caringin No 353 Padalarang. Divisi Noodle merupakan divisi terbesar PT Indofood CBP Sukses Makmur Tbk, dan sampai saat ini terdapat 16 pabrik yang tersebar di kota-kota besar di Indonesia, seperti dapat disimak pada Tabel 1. Divisi Noodle PT Indofood CBP Sukses Makmur Tbk Cabang Bandung bertanggung jawab atas pemasaran produk dan memberikan pelatihan kepada setiap karyawannya yang melingkupi daerah Jawa Barat saja. 
Tabel 1. Nama lokasi Divisi Noodle

\begin{tabular}{lll}
\hline Nama Lokasi & \multicolumn{1}{c}{ Pembagian Lokasi } & \multicolumn{1}{c}{$\begin{array}{c}\text { Pembagian Lokasi Secara } \\
\text { Tersebar }\end{array}$} \\
\hline Sumatera & Sumatera Utara & Medan \\
& Riau & Pekan Baru \\
& Sumatera Selatan & Palembang \\
& Sumatera Selatan & Jambi \\
& Lampung & Bandar Lampung \\
\hline Jawa & DKI Jakarta & Jakarta \\
& Banten & Tanggerang \\
& Jawa Barat & Cibitung \\
& Jawa Barat & Bandung \\
& Jawa Tengah & Semarang \\
& Jawa Timur & Pasuruan \\
\hline Kalimantan & Kalimantan Selatan & Banjarmasin \\
& Kalimantan Barat & Pontianak \\
\hline Sulawesi & Sulawesi Utara & Manado \\
& Sulawesi Selatan & Makasar \\
\hline
\end{tabular}

Pentingnya dilakukan penelitian ini, selain untuk mengevaluasi penerapan budaya kerja perusahaan, juga untuk mengetahui dan memberikan informasi tentang faktor-faktor yang berpengaruh dan perlu diperbaiki.Tujuan penelitian ini adalah: 1) mengidentifikasi budaya kerja pada PT Indofood CBP Sukses Makmur Tbk Cabang Bandung Divisi Noodle; 2) mengidentifikasi komitmen kerja pada PT Indofood CBP Sukses Makmur Tbk Cabang Bandung Divisi Noodle; 3) menganalisis pengaruh budaya kerja terhadap komitmen karyawan di PT Indofood CBP Sukses Makmur Tbk Cabang Bandung Divisi Noodle.

\section{Metode Penelitian}

Penelitian mengenai pengaruh budaya kerja PT Indofood CBP Sukses Makmur Tbk Cabang Bandung Divisi Noodle, diawali dengan mengidentifikasi budaya kerja, komitmen karyawan, serta akhirnya menganalisis pengaruh budaya kerja terhadap komitmen karyawan Divisi Noodle Cabang Bandung. Data untuk analisis mengenai pengaruh budaya kerja terhadap komitmen dikumpulkan melalui wawancara, pengamatan langsung, serta dokumen yang dimiliki oleh perusahaaan. Berdasarkan hasil analisis, dapat diajukan beberapa usulan atau koreksi terhadap apa yang telah dilakukan perusahaan. Penelitian dilaksanakan di PT Indofood CBP Sukses Makmur Tbk Cabang Bandung yang berlokasi di Jl. Caringin No. 353 Padalarang Bandung Barat, dari bulan November 2013 sampai dengan Februari 2014. Budaya perusahaan sering juga disebut budaya kerja. Pada variabel budaya kerja dan komitmen karyawan dilihat hubungan antara indikator-indikator kedua variabel tersebut. Kerangka pemikiran penelitian ini dapat dilihat pada Gambar 1.

Data primer yang digunakan, diperoleh dari karyawan PT Indofood CBP Sukses Makmur Tbk Cabang Bandung Divisi Noodle. Seluruh bidang dan divisi yang ada di perusahaan ini dijadikan contoh sebagai responden. Data sekunder diperoleh mencakup teori dan hasil study mengenai budaya kerja dan komitmen karyawan yang diperoleh dari buku, beragam literatur dan internet. Pendekatan kesikapan merupakan 
pendekatan paling terkenal untuk mengkonseptualisasikan komitmen organisasional. Komitmen organisasional didefinisikan sebagai kekuatan relatif identifikasi dan keterlibatan individual dalam organisasi tertentu (Runing 2011). Penelitian ini merupakan studi lapangan yang menggunakan metodesesuai yang dibutuhkan (purposive sampling), dengan menggunakan kuesioner sebagai alat pengumpulan data (Purba dan Seniati 2004).

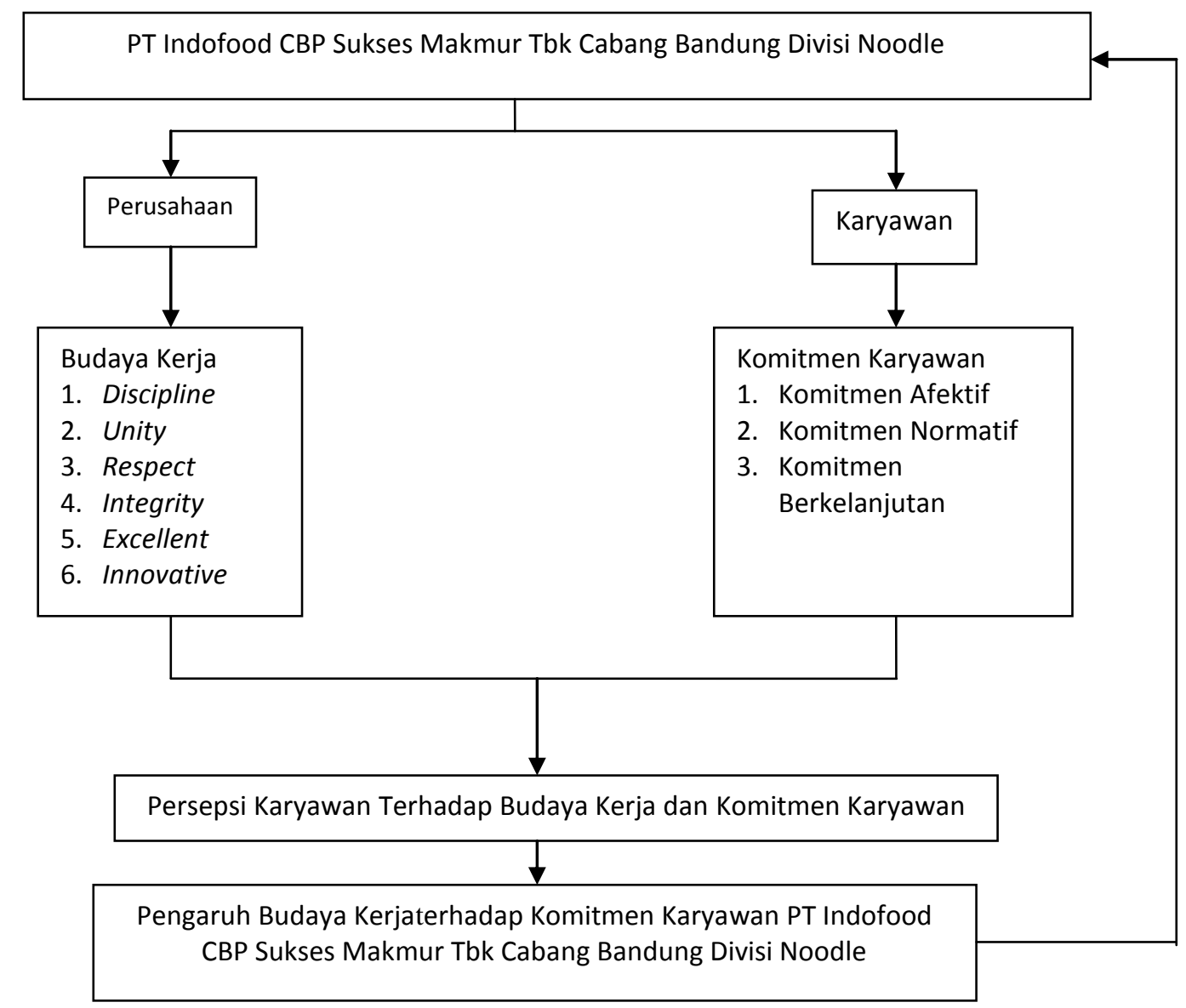

Gambar 1. Kerangka pemikiran

Teknik penarikan contoh yang digunakan dalam penelitian ini adalah purposive sampling, dimana teknik pengambilan sampel didasarkan pada pertimbangan tertentu. Teknik ini bisa diartikan sebagai suatu proses pengambilan sampel dengan menentukan terlebih dulu jumlah sampel yang hendak diambil, kemudian pemilihan contoh dilakukan dengan tujuan-tujuan tertentu dengan tidak memberikan kesempatan yang sama kepada seluruh karyawan.

Berdasarkan catatan terdapat 1500 karyawan di Divisi Noodle Cabang Bandung yang tersebar di 5 departemen, yaitu Departemen Personalia, Pemasaran, Keuangan, Produksi dan Quality Control. Masing-masing departemen diambil 20 sampel, sehingga total sampel adalah 100. 
Regresi linear Berganda adalah regresi dimana variabel terikatnya ( $Y$ ) dijelaskan lebih dari satu variabel bebas $(\mathrm{X} 1, \mathrm{X} 2, \mathrm{X} 3, \ldots ., \mathrm{Xn})$ namun masih menunjukkan diagram hubungan yang linear. Rumus regresi linear berganda adalah:

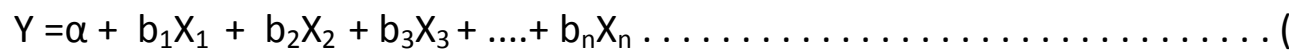

Menurut Sugiono (2006), diperlukan suatu langkah pengujian terhadap isi dari suatu instrumen, dengan tujuan untuk mengukur ketepatan instrumen yang digunakan dalam suatu penelitian. Reliabilitas atau keandalan suatu pengukuran menunjukkan sejauh mana pengukuran tersebut tanpa bias (bebas dari kesalahan) dan karena itu menjamin pengukuran yang konsisten lintas waktu dan lintas beragam item dalam instrument. Dengan kata lain, keandalan suatu pengukuran merupakan indikasi mengenai stabilitas dan konsistensi dimana instrument mengukur konsep dan membantu menilai ketepatan sebuah pengukuran. Pengujian dalam penelitian ini menggunakan uji alpha cronbach, yang digunakanuntuk menguji reliabilitas instrumen yang menggunakan skala Likert.

\section{Hasil dan Pembahasan}

\section{III.1. Gambaran Umum Perusahaan}

PT Indofood CBP Sukses Makmur Tbk Cabang Bandung Divisi Noodle pertama kali didirikan pada bulan Mei tahun 1992. Pada awal berdirinya, industri ini bernama PT Karya Pangan Sejati yang merupakan salah satu cabang dari Sammaru Food Manufacturing Co Ltd yang berpusat di Jakarta. PT Indofood CBP Sukses Makmur Tbk Cabang Bandung ini berfokus dalam memproduksi mie instan sesuai dengan bidang produksi sebelumnya. Pada tahun 2009, industri ini mendapat sisipan nama CBP menjadiPT Indofood CBP Sukses Makmur Tbk Cabang Bandung Divisi Noodle. Akronim CBP yang tersemat pada nama industri ini merupakan kependekan dari Consumer Brand Product yang menunjukan bahwa perusahaan ini merupakan bagian dari group produk konsumen bermerek.

PT Indofood CBP Sukses Makmur Tbk Cabang Bandung Divisi Noodle mempunyai visi dan misi. Adapun tujuan perusahaan yaitu:

1. Menjadi Total Food Solutions Company

2. Untuk terus meningkatkan karyawan kami, proses kami dan teknologi kami

3. Untuk memastikan ketersediaan produk-produk kami kepada pelanggan domestik dan Internasional

4. Untuk memberikan kontribusi pada peningkatan kualitas hidup masyarakat Indonesia dengan perkenaan pada gizi

5. Untuk terus meningkatkan Stakeholder's value.

Aplikasi yang diberikan oleh suatu perusahaan kepada karyawan PT Indofood CBP Sukses Makmur Tbk Cabang Bandung Divisi Noodle sudah efektif. Hal ini dibuktikan dengan tersertifikasinya Standarisasi Sistem Manajemen Mutu Produk ISO 9002 pada tanggal 4 Desember 1998. Sertifikasi tersebut diperoleh industri ini karena aspek kesegaran, kepraktisan, keamanan, kehalalan, kehigienisan, kandungan gizi dan rasa produk yang dihasilkan selalu diperhatikan. Industri ini juga mendapatkan 
sertifikat ISO 9001 yang diserahkan di Jakarta pada tanggal 3 Maret 1999. Pada tanggal 15 Februari 2004, industri ini kembali mendapatkan sertifikat ISO mengenai sistem Manajemen Mutu yaitu ISO 9001:2001.

\section{III.2. Karakteristik Responden}

Karakteristik responden dalam penelitian ini terdiri dari :

\section{Jenis Kelamin}

Jumlah responden perempuan lebih banyak dibandingkan dengan jumlah lakilaki terutama di bagian Departemen Produksi, karena peran perempuan di PT Indofood CBP Sukses Makmur Tbk Cabang Bandung Divisi Noodle sangat dibutuhkan untuk kegiatan pengepakan (packing), isi bumbu dan isi minyak.

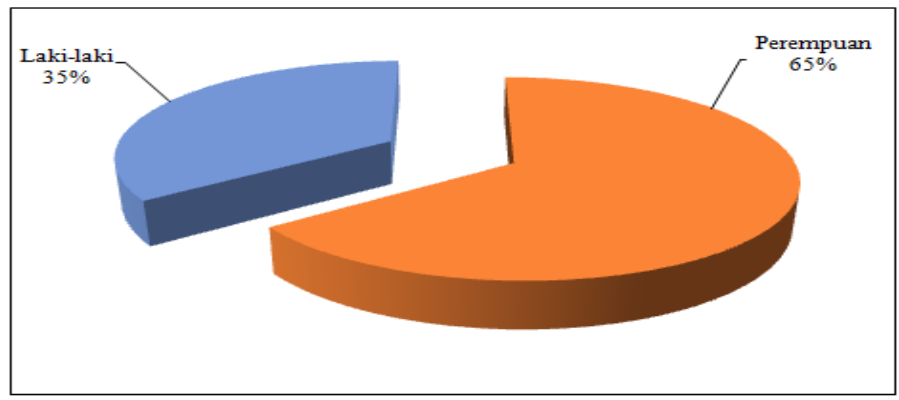

Gambar 2. Jumlah responden berdasarkan jenis kelamin

2. Usia

Jumlah responden pada usia 18-28 tahun lebih banyak dibandingkan yang lainnya. Hal ini karena usia tersebut, bagi PT Indofood CBP Sukses Makmur Tbk Cabang Bandung Divisi Noodle merupakan usia produktif.

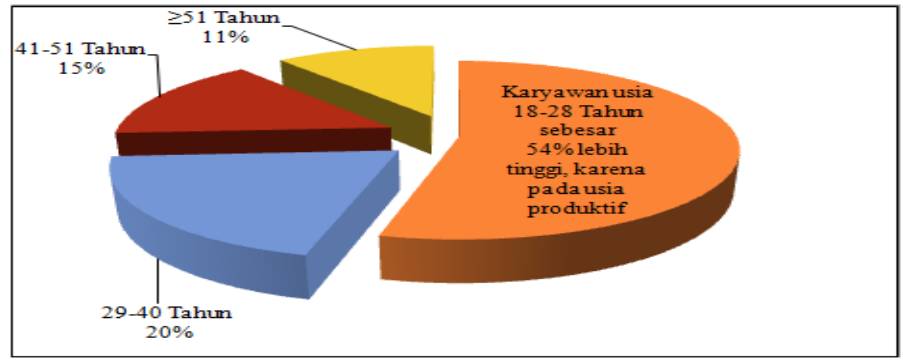

Gambar 3. Jumlah responden berdasarkan usia

\section{Tingkat Pendidikan}

Jumlah responden yang berpendidikan SMA atau SMK adalah yang tertinggi dibandingkan dengan yang berpendidikan lainnya. PT Indofood CBP Sukses Makmur Tbk Cabang Bandung Divisi Noodle berdiri sejak tahun 1992 dan banyak karyawan yang hampir 22 tahun bekerja di perusahaan ini. Pada tahun 1992 mayoritas karyawan di perusahaan ini berpendidikan setingkat SMA atau sederajat. Oleh karena itu, perusahaan lebih menghargai lama kerja, walau tidak menutup kemungkinan juga menerima S1 untuk ditempatkan pada posisi lebih tinggi dibandingkan dengan pendidikan SMA. 


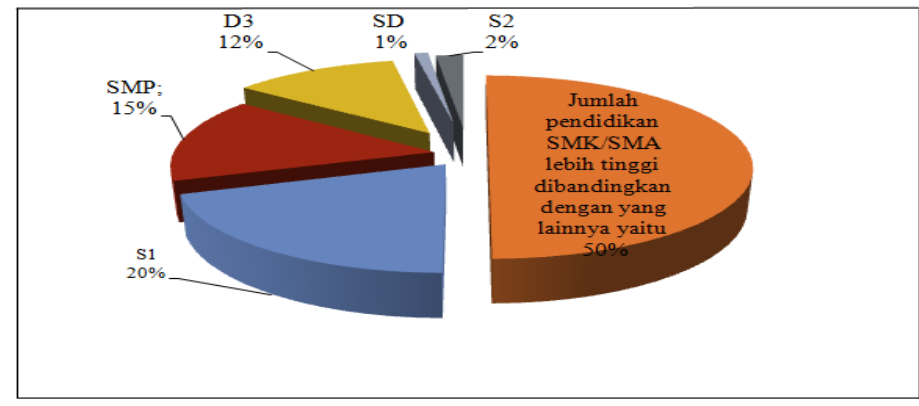

Gambar 4. Jumlah responden berdasarkan pendidikan

4. Jabatan atau posisi pekerjaan

Responden yang menempati jabatan sebagai Supervisor sebanyak $60 \%$, Staff $25 \%$ dan sisanya adalah Manajer 15\%.

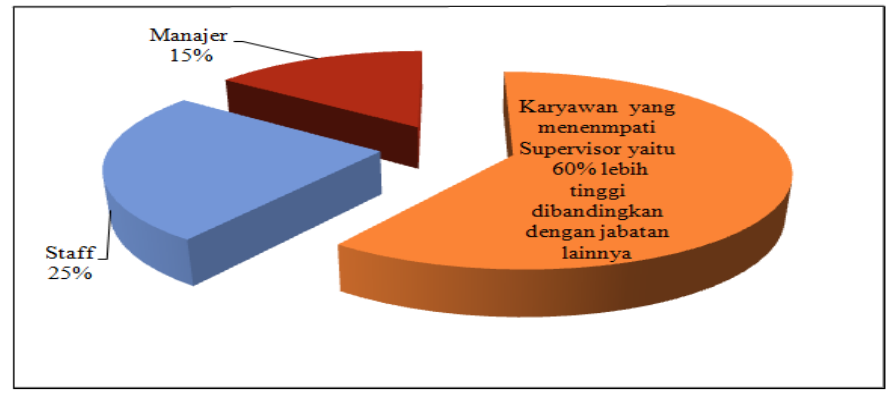

Gambar 5. Jumlah responden berdasarkan posisi pekerjaan

\section{Masa Kerja}

Jumlah responden yang memiliki masa kerja $5 \geq 25$ tahun sebesar $70 \%$, 4 tahun 9\%, 3 tahun 4\%, 2 tahun 5\%, 1 tahun (2\%) dan $<1$ tahun 10\%. Karyawan dengan masa kerja $5 \geq 25$ tahun lebih tinggi dibandingkan dengan masa kerja lainnya. Hal ini karena PT Indofood CBP Sukses Makmur Tbk Cabang Bandung Divisi Noodle telah didirikan cukup lama (tahun 1992) dan banyak karyawan yang telah bekerja pada saat perusahaan ini didirikan.

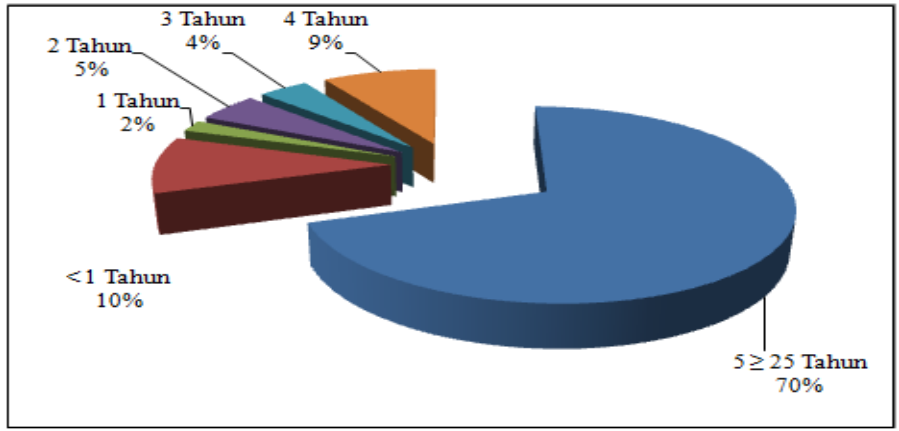

Gambar 6. Jumlah responden berdasarkan masa pekerjaan

6. Status Pernikahan

Responden yang telah menikah dan belum menikah tidak berbeda jauh ( $56 \%$ dan $44 \%)$. 


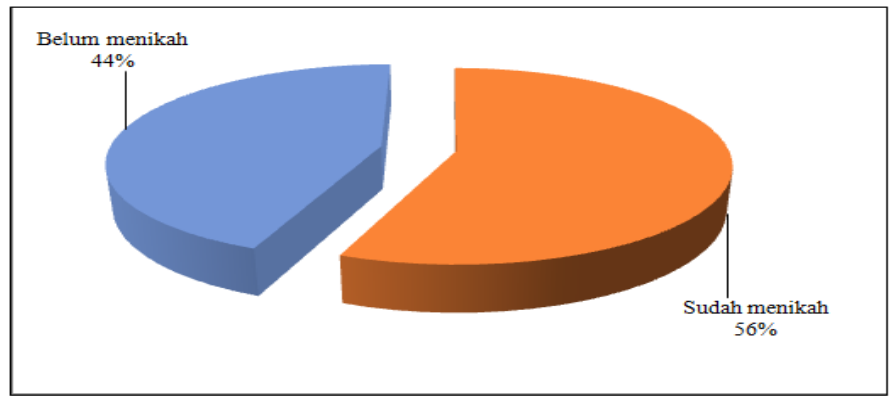

Gambar 7. Jumlah responden berdasarkan status pernikahan

\section{III.3. Persepsi Karyawan terhadap Budaya Kerja dan Komitmen Karyawan}

Penerapan budaya kerja pada karyawan PT Indofood CBP Sukses Makmur Tbk Cabang Bandung Divisi Noodle dapat dilihat dari jumlah mayoritas jawaban pertanyaan karyawan. Intrepretasi jawaban karyawan tentang budaya kerja dan komitmen karyawan digunakan rataan nilai skor diperoleh dengan mengalikan jumlah responden dengan bobot nilai jawaban berdasarkan skalanya. Setelah nilai rataan diperoleh, selanjutnya menentukan rentang skala. Penelitian ini menggunakan skala Likert 1-5. Rentang skala (RS) dihitung dengan cara :

$$
\mathrm{RS}=\frac{(5-1)}{5}=0.8
$$

Keterangan : 5 adalah nilai tertinggi dari jawaban responden dan 1 adalah nilai yang terendah

Selanjutnya, untuk menentukan penilaian karyawan terhadap beragam pernyataan yang berhubungan dengan budaya kerja dan komitmen karyawan dilakukan dengan skor rataan dengan nilai dapat dilihat pada Tabel 2 .

Tabel 2. Kriteria penilaian skor untuk budaya kerja dan komitmen karyawan

\begin{tabular}{ccc}
\hline Nilai Skor Rataan & Keterangan Budaya Kerja & $\begin{array}{c}\text { Keterangan Komitmen } \\
\text { Karyawan }\end{array}$ \\
\hline $1.00-1.80$ & Sangat Tidak Setuju & Sangat Tidak Setuju \\
$1.81-2.60$ & Tidak Setuju & Tidak Setuju \\
$2.61-3.40$ & Kurang Setuju & Kurang Setuju \\
$3.41-4.20$ & Setuju & Setuju \\
$4.21-5.00$ & Sangat Setuju & Sangat Setuju \\
\hline
\end{tabular}

\section{Persepsi Karyawan terhadap Budaya Kerja Divisi Noodle Cabang Bandung}

Organisasi membutuhkan kepemimpinan yang kuat untuk pencapaian efektivitas yang optimal. Pada era ini dimana dunia memiliki dinamika yang fluktuatif, dibutuhkan pemimpin yang mampu menantang kondisi status-quo, menciptakan visi yang jauh ke depan, serta mampu menginspirasi para anggota organisasinya untuk mau mencapai visi tersebut (Robbins 2003).

Budaya kerja yang dimiliki Divisi Noodle Cabang Bandung terdiri dari discipline, unity, respect, integrity, excellent, innovative. Hasil pengolahan data diperoleh gambaran tentang persepsi karyawan mengenai penerapan budaya kerja pada Divisi Noodle Cabang Bandung dapat dilihat pada Tabel 3. 
Tabel 3. Persepsi karyawan terhadap budaya kerja Divisi Noodle Cabang Bandung

\begin{tabular}{lcc}
\hline \multicolumn{1}{c}{ Indikator } & Skor Rataan & Keterangan \\
\hline Discipline & 4.19 & Setuju \\
Unity & 4.16 & Setuju \\
Respect & 4.24 & Sangat Setuju \\
Integrity & 4.26 & Sangat Setuju \\
Excellent & 4.21 & Sangat Setuju \\
Innovative & 4.18 & Setuju \\
\hline
\end{tabular}

Penjelasan atas persepsi karyawan terhadap budaya kerja yang diterapkan, yaitu :

a. Budaya Kerja Discipline

Karyawan perusahaan setuju, bahwa perusahaan telah menerapkan budaya kerja disiplin. Salah satunya, perusahaan menuntut karyawan untuk datang tepat waktu di kantor setiap hari. Hal tersebut merupakan hal positif yang harus dikerjakan dengan penuh tanggung jawab, sehingga budaya disiplin dapat diterima oleh karyawan.

b. Budaya Kerja Unity

Karyawan perusahaan secara keseluruhan menunjukkan jawaban setuju. Karyawan setuju karena perusahaan memberikan pergantian kerja atau shift kerja sesuai dengan jadwal kerja. Setiap karyawan dituntut untuk saling bekerja sama.

c. Budaya kerja Respect

Karyawan perusahaan sangat setuju, apabila perusahaan telah menerapkan budaya kerja respect. Salah satunya adalah perusahaan memberikan penghargaan kepada karyawan yang berprestasi, menuntut karyawan agar bisa menjaga sikap, serta dalam berkomunikasi menggunakan bahasa yang mencerminkan rasa hormat.

d. Budaya Kerja Integrity

Karyawan perusahaan sangat setuju, apabila perusahaan telah menerapkan budaya kerja Integrity. Karyawan setuju karena perusahaan memberikan peraturan yang positif kepada karyawan, antara lain karyawan dituntut untuk bersikap jujur, bertanggung jawab dalam bekerja, serta mengerjakan pekerjaan sesuai dengan peraturan perusahaan.

e. Budaya Kerja Excellent

Karyawan perusahaan sangat setuju, apabila perusahaan telah menerapkan budaya kerja Excellent. Karyawan setuju karena perusahaan menuntut agar pekerjaan yang ditekuni memunculkan keunggulan, karyawan dituntut untuk jarang membuat kesalahan dalam bekerja serta dituntut untuk terus belajar dan mengembangkan diri.

f. Budaya Kerja Innovative

Karyawan perusahaan setuju, apabila perusahaan telah menerapkan budaya kerja Innovative. Karyawan setuju karena perusahaan memberikan kesempatan kepada karyawan untuk mengembangkan diri melalui program pelatihan, memberikan kebebasan kepada karyawan dalam menjalankan tugasnya, serta memberikan kesempatan kepada karyawan untuk mengemukakan ide. 
2. Persepsi Karyawan terhadap Komitmen Karyawan PT Indofood CBP Sukses Makmur Tbk Cabang Bandung Divisi Noodle.

Menurut Allen dan Meyer (2004), komitmen terbagi atas tiga komponen yaitu : 1) Komitmen afektif (affective commitment), yaitu komitmen yang berkaitan dengan emosional, identifikasi, dan keterlibatan karyawan di dalam suatu organisasi. Karyawan dengan afektif tinggi masih bergabung dengan organisasi karena keinginan untuk tetap menjadi anggota organisasi; 2) Komitmen normatif (normative commitment), yaitu komitmen karyawan tentang kewajiban yang harus diberikan kepada organisasi. Komponen normatif berkembang sebagai hasil dari pengalaman sosialisasi, tergantung dari sejauh apa perasaan kewajiban yang dimiliki karyawan. Komponen normatif menimbulkan perasaan kewajiban kepada karyawan untuk memberikan balasan atas apa yang pernah diterimanya dari organisasi; dan 3) Komitmen berkelanjutan (continuance commitment), yaitu komponen yang berdasarkan persepsi karyawan tentang kerugian yang akan dihadapinya jika meninggalkan organisasi. Hal ini terjadi karena karyawan tersebut membutuhkan organisasi. Karyawan yang memiliki komitmen organisasi dengan dasar afektif memiliki tingkah laku yang berbeda dengan karyawan dengan dasar continuance. Karyawan yang ingin menjadi anggota akan memiliki keinginan untuk berusaha yang sesuai dengan tujuan organisasi.

Karyawan memberikan tanggapan terhadap kondisi komitmen karyawan yang diterapkan oleh PT Indofood CBP Sukses Makmur Tbk Cabang Bandung Divisi Noodle, artinya karyawan bersedia untuk mentaati semua peraturan perusahaan dan aturanaturan yang berlaku.

Tabel 4. Persepsi karyawan terhadap komitmen karyawan Divisi Noodle Cabang Bandung

\begin{tabular}{lcc}
\hline \multicolumn{1}{c}{ Variabel } & Skor Rataan & Keterangan \\
\hline Affective Commitment & 4.30 & Sangat Setuju \\
Normative Commitmen & 4.13 & Setuju \\
Continuance Commitment & 4.24 & Sangat Setuju \\
\hline
\end{tabular}

Penjelasan atas persepsi karyawan terhadap komitmen kerja adalah :

a. Affective Commitment

Karyawan memberikan tanggapan sangat setuju dengan komitmen afektiv, artinya karyawan bersedia mematuhi komitmen dengan melaksanakan kewajibannya, karyawan merasa nyaman, serta merasa bangga menjadi bagian perusahaan.

b. Normative Commitment

Karyawan memberikan tanggapan setuju dengan komitmen normatif, artinya karyawan bersedia mematuhi komitmen untuk bekerja dengan produktivitas tinggi, merasa berat dan rugi meninggalkan perusahaan, serta tetap bertahan walaupun mendapatkan tawaran dari perusahaan lain.

c. Continuance Commitment

Karyawan memberikan tanggapan sangat setuju dengan komitmen berkelanjutan, artinya karyawan membantu dalam kesuksesan perusahaan, memberikan kesetiaan didalam bekerja, saling memberikan masukan dan pelatihan, mempunyai kewajiban yang harus dijalankan, serta merasa mendapatkan pelajaran yang banyak pada saat bekerja. 


\section{III.4. Uji Normalitas}

Hasil uji normalitas residual menunjukkan residual telah menyebar normal. Pada Gambar 8 terlihat bahwa bentuk histogram menyerupai bentuk sebaran normal dan pada plot titik-titiknya tersebar hampir mendekati garis lurus. Sehingga dapat disimpulkan asumsi kenormalan terpenuhi.

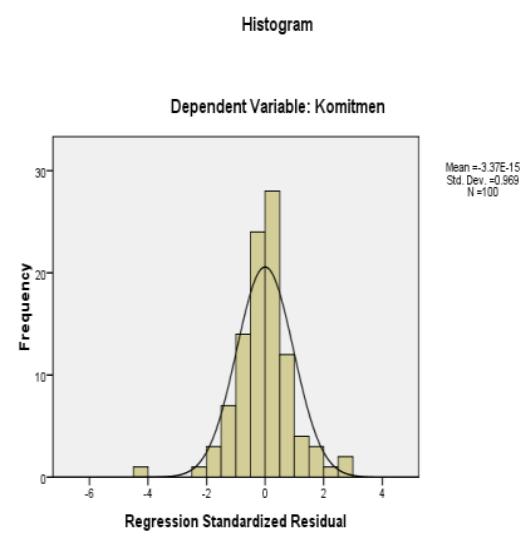

Normal P.P Plot of Regression Standardized Residual

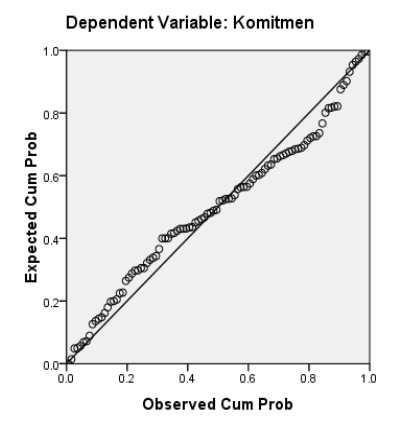

Gambar 8. Histogram peluang normal

\section{III.5. Uji Autokorelasi}

Hasil uji autokorelasi menunjukkan nilai Durbin-Watson sebesar 2.124, dimana nilai ini mendekati 2, maka dapat disimpulkan tidak terjadi autokorelasi.

Tabel 5. Hasil uji autokorelasi

\begin{tabular}{cccccc}
\hline \multicolumn{5}{c}{ Model Summary } \\
\hline Model & $\mathrm{R}$ & R Square & Adjusted R Square & Std. Error of the Estimate & Durbin-Watson \\
\hline 1 & $.971^{\mathrm{a}}$ & .943 & .939 & 1.02401 & 2.124 \\
\hline
\end{tabular}

III.6. Uji Multikolinearitas

Pada Tabel 6 terlihat bahwa nilai VIF dari seluruh variabel independen tidak melebihi 10, maka dapat disimpulkan tidak ada multikolinearitas.

Tabel 6. Hasil uji multikolinearitas

\begin{tabular}{clcc}
\hline No & Variabel Independen (Variabel X) & Alpha ( $\boldsymbol{\alpha})$ & VIF \\
\hline 1 & Unity & 0.05 & 2.214 \\
2 & Discipline & 0.05 & 2.514 \\
3 & Respect & 0.05 & 2.147 \\
4 & Integrity & 0.05 & 1.623 \\
5 & Excellent & 0.05 & 1.880 \\
6 & Innovatif & 0.05 & 1.819 \\
\hline
\end{tabular}

Setelah uji asumsi klasik, maka perlu dilakukan pengujiam hipotesis untuk melihat pengaruh budaya kerja terhadap komitmen. Pada pengujian hipotesis dilakukan dua uji yaitu uji koefisien regresi secara parsial (Uji t) dan uji koefisien regresi secara bersama-sama (Uji F) pada taraf alpha $5 \%$. 
160| Hermayanti, Rahmawati - Pengaruh Budaya Kerja terhadap Komitmen Karyawan

\section{III.7. Uji Koefisien Regresi Secara Bersama-sama (Uji F)}

Uji ini digunakan untuk mengetahui apakah variabel independen secara bersama-sama berpengaruh secara signifikan terhadap variabel dependen. Uji $F$ memiliki hipotesis, yaitu : tolak $\mathrm{H}_{0}$ atau terima $\mathrm{H}_{1}$ Jika $\mathrm{P}$-value $<\alpha$ dan terima $\mathrm{H}_{0}$ atau tolak $\mathrm{H}_{1}$ jika $\mathrm{P}$-value $>$ a pada taraf alpha $5 \%$.

$\mathrm{H}_{0}$ : tidak terdapat pengaruh secara signifikan budaya kerja terhadap komitmen karyawan

$\mathrm{H}_{1}$ : terdapat pengaruh secara signifikan budaya kerja terhadap komitmen karyawan

Hasil Uji F yang dilakukan menunjukkan nilai P-value sebesar 0.000, dimana nilai ini lebih kecil dari nilai alpha yaitu sebesar 0.05 . Karena nilai $P_{\text {value }}<\alpha(0.000<0.05)$, maka tolak $\mathrm{H}_{0}$ dan terima $\mathrm{H}_{1}$ yang artinya secara parsial terdapat pengaruh budaya kerja terhadap komitmen karyawan.

\section{III.8. Uji Koefisien Regresi secara Parsial (Uji t)}

Hasil uji koefisien regresi dapat dilihat di Tabel 7. Dirumuskan hipotesis pada penelitian ini yaitu tolak $\mathrm{H}_{0}$ atau terima $\mathrm{H}_{1}$ jika $\mathrm{P}$-value $<\alpha$ dan terima $\mathrm{H}_{0}$ atau tolak $\mathrm{H}_{1}$ jika P-value $>$ a pada taraf alpha 5\%.

$\mathrm{H}_{0}$ : budaya kerja tidak berpengaruh secara signifikan terhadap komitmen karyawan

$\mathrm{H}_{1}$ : budaya kerja berpengaruh secara signifikan terhadap komitmen karyawan

Tabel 7. Hasil analisis uji t

\begin{tabular}{clccc}
\hline No & Variabel Independen & Alpha $(\boldsymbol{\alpha})$ & $\mathbf{P}_{\text {value }}$ & Kesimpulan \\
\hline 1 & Unity & 0.05 & 0.427 & Tidak berpengaruh \\
2 & Discipline & 0.05 & 0.000 & Berpengaruh \\
3 & Respect & 0.05 & 0.000 & Berpengaruh \\
4 & Integrity & 0.05 & 0.000 & Berpengaruh \\
5 & Excellent & 0.05 & 0.000 & Berpengaruh \\
6 & Innovatif & 0.05 & 0.025 & Berpengaruh \\
\hline
\end{tabular}

III.9. Analisis Regresi Linear Berganda

Analisis regresi linear berganda digunakan untuk menguji hubungan pengaruh antara satu variabel terhadap variabel lain. Data pada analisis linear berganda merupakan data parametrik. Berdasarkan hasil analisis regresi linear berganda diperoleh model regresi sebagai berikut :

$Y=45.6+0.012 X_{1}+0.087 X_{2}+0.072 X_{3}+0.114 X_{4}+0.143 X_{5}+0.038 X_{6}$

Keterangan:

$Y$ : Komitmen karyawan

$\mathrm{X}_{1}$ : Budaya kerja unity

$\mathrm{X}_{2}$ : Budaya kerja discipline

$\mathrm{X}_{3}$ : Budaya kerja respect

$\mathrm{X}_{4}$ : Budaya kerja integrity

$\mathrm{X}_{5}$ : Budaya kerja Excellent

$\mathrm{X}_{6}$ : Budaya kerja Innovative 
Berdasarkan hasil analisis regresi linear berganda, diperoleh koefisien variabel budaya kerja unity $\left(X_{1}\right) 0.012$, koefisien budaya kerja discipline $\left(X_{2}\right) 0.087$, koefisien budaya kerja respect $\left(X_{3}\right) 0.072$, koefisien budaya kerja integrity $\left(X_{4}\right) 0.114$, koefisien budaya kerja excellent $\left(\mathrm{X}_{5}\right)$ 0.143, dan koefisien budaya kerja Innovative $\left(\mathrm{X}_{6}\right) 0.038$. Model regresi yang dihasilkan mempunyai arti yaitu:

1. Koefisien budaya kerja unity sebesar 0.012, artinya jika budaya kerja meningkat dengan cateris paribus dan independen lainnya (discipline, respect, integrity, excellent, innovative) dianggap konstan, tapi karena unity tidak berpengaruh pada komitmen, maka komitmen karyawan tidak akan meningkat sebesar 0.012 .

2. Koefisien budaya kerja discipline sebesar 0.087 , artinya jika budaya kerja meningkat dengan cateris paribus dan independen lainnya (unity, respect, integrity, excellent, innovative) dianggap konstan, maka komitmen karyawan berpotensi akan meningkat sebesar 0.087 , koefisien bernilai positif artinya terjadi hubungan yang positif antara budaya kerja discipline dengan komitmen karyawan.

3. Koefisien budaya kerja respect sebesar 0.072, artinya jika budaya kerja meningkat dengan cateris paribus dan independen lainnya (unity, discipline, integrity, excellent, innovative) dianggap konstan, maka komitmen karyawan berpotensi akan meningkat sebesar 0.087 , koefisien bernilai positif artinya terjadi hubungan yang positif antara budaya kerja respect dengan komitmen karyawan.

4. Koefisien budaya kerja integrity sebesar 0.114 , artinya jika budaya kerja meningkat dengan cateris paribus dan independen lainnya (unity, respect, respect, excellent, innovative) dianggap konstan, maka komitmen karyawan berpotensi akan meningkat sebesar 0.114 , koefisien bernilai positif artinya terjadi hubungan yang positif antara budaya kerja integrity dengan komitmen karyawan.

5. Koefisien budaya kerja excellent sebesar 0.143 , artinya jika budaya kerja meningkat dengan cateris paribus dan independen lainnya (unity, respect, integrity, integruty, innovative) dianggap konstan, maka komitmen karyawan berpotensi akan meningkat sebesar 0.087 , koefisien bernilai positif artinya terjadi hubungan yang positif antara budaya kerja excellent dengan komitmen karyawan.

6. Koefisien budaya kerja innovative sebesar 0.087, artinya jika budaya kerja meningkat dengan cateris paribus dan independen lainnya (unity, respect, integrity, excellent, exccellent) dianggap konstan, maka komitmen karyawan berpotensi akan meningkat sebesar 0.087 , koefisien bernilai positif artinya terjadi hubungan yang positif antara budaya kerja innovative dengan komitmen karyawan.

\section{III.9. Implikasi Manajerial}

PT Indofood CBP Sukses Makmur Tbk Cabang Bandung Divisi Noodle menerapkan budaya kerja excellent kepada karyawan dalam menjalankan dan mendukung kinerjanya danPT Indofood CBP Sukses Makmur Tbk telah menerapkannya dengan baik. Karyawan setuju dengan adanya komitmen karyawan yang ditetapkan yang artinya karyawan bersedia untuk melakukan peraturan atau komitmen karyawan yang ditetapkan oleh PT Indofood CBP Sukses Makmur Tbk Cabang Bandung Divisi Noodle, namun sebaiknya perusahaan melakukan monitoring pada saat karyawan bekerja. Selain melakukan monitoring, perlu adanya dukungan dan keseimbangan dari divisi lain yang ada diPT Indofood CBP Sukses Makmur Tbk, dan mensinergikan beberapa 
faktor dan variabel yang ada untuk meningkatkan motivasi kerja karyawan di sebuah perusahaan dalam menjalankan budaya kerja dan komitmen karyawan. PT Indofood CBP Sukses Makmur Tbk juga harus memperhatikan kehadiran dan sistem informasi yang ada di perusahaan karena hal tersebut merupakan pendukung budaya kerja dan komitmen di suatu perusahaan.

\section{Kesimpulan}

Berdasarkan pembahasan hasil penelitian yang telah diuraikan dapat dikemukakan kesimpulan bahwa budaya kerja PT Indofood CBP Sukses Makmur Tbk Cabang Bandung Divisi Noodle adalah excellent. Karyawan setuju dengan adanya komitmen karyawan yang ditetapkan yang artinya karyawan bersedia untuk melakukan peraturan atau komitmen karyawan yang ditetapkan oleh PT Indofood CBP Sukses Makmur Tbk Cabang Bandung Divisi Noodle. Budaya kerja yang memiliki pengaruh signifikan dan positif terhadap komitmen karyawan adalah excellent, discipline, perfect, integrity, innovative, sedangkan budaya kerja unity tidak berpengaruh signifikan terhadap komitmen.

\section{Daftar Pustaka}

Allen JN, Meyer PJ. 1990. The measurement and antecedents of affective, continuance and normative commitment to the organization. Journal of Occupational psychology, 63(1): 1-18.DOI: 10.1111/j.2044-8325.1990.tb00506.x.

Gibson. 1996. Organisasi: Perilaku, Struktur dan Proses dan Komitmen. Jakarta (ID): Alfabeta.

Ivancevich JM, Konopaske R, Matteson MT. 2005. Perilaku dan Manajemen Organisasi, Edisi Ketujuh. Jakarta (ID): Erlangga.

Kurniawan D, Lubis AR, Adam M. 2012. Pengaruh budaya kerja dan motivasi kerja terhadap kinerja karyawan Internasional Federation Red Cross Banda Aceh. Jurnal IImu Manajemen [Internet]. [diunduh 2014 Agustus 1]; 1(1): 132-146. Tersedia pada: http://prodipps.unsyiah.ac.id.

Moeljono D. 2005. Good Corporate Culture. Jakarta (ID): Elex Computindo.

Mustika IK. 2012. Analisis budaya organisasi dan kepuasan kerja melalui komitmen pengaruhnya terhadap intent to leave karyawan pada industri jasa perhotelan di Kabupaten Bandung. Jurnal Mitra Ekonomi dan Manajemen Bisnis, 3: 1-24.

Purba DE, Seniati ANL. 2004. Pengaruh kepribadian dan komitmen organisasi terhadap organizational behavior citizenzhip. Makara, Sosial Humaniora [Internet]. [diunduh 2014 Desember 3]; 8(3): 105-111. Tersedia pada: http://repository.ui.ac.id.

Robbins SP. 2003. Organizational Behavior. New Jersey (US): Prentice Hall upmpublisher.

Runing HS. 2011. Jarak kekuasaan sebagai pemoderasi pengaruh keadilan organisasional terhadap komitmen karyawan pada supervisor. Jurnal Manajemen Teori dan Terapan, 4 (3): 25-36.

Sugiono. 2006. Statistika Untuk Penelitian. Bandung (ID): Alfabeta. 